\title{
Recordando Pedro Marques da Silva
}

\section{In Memorium: Pedro Marques da Silva}

\section{Mário Espiga de Macedo}

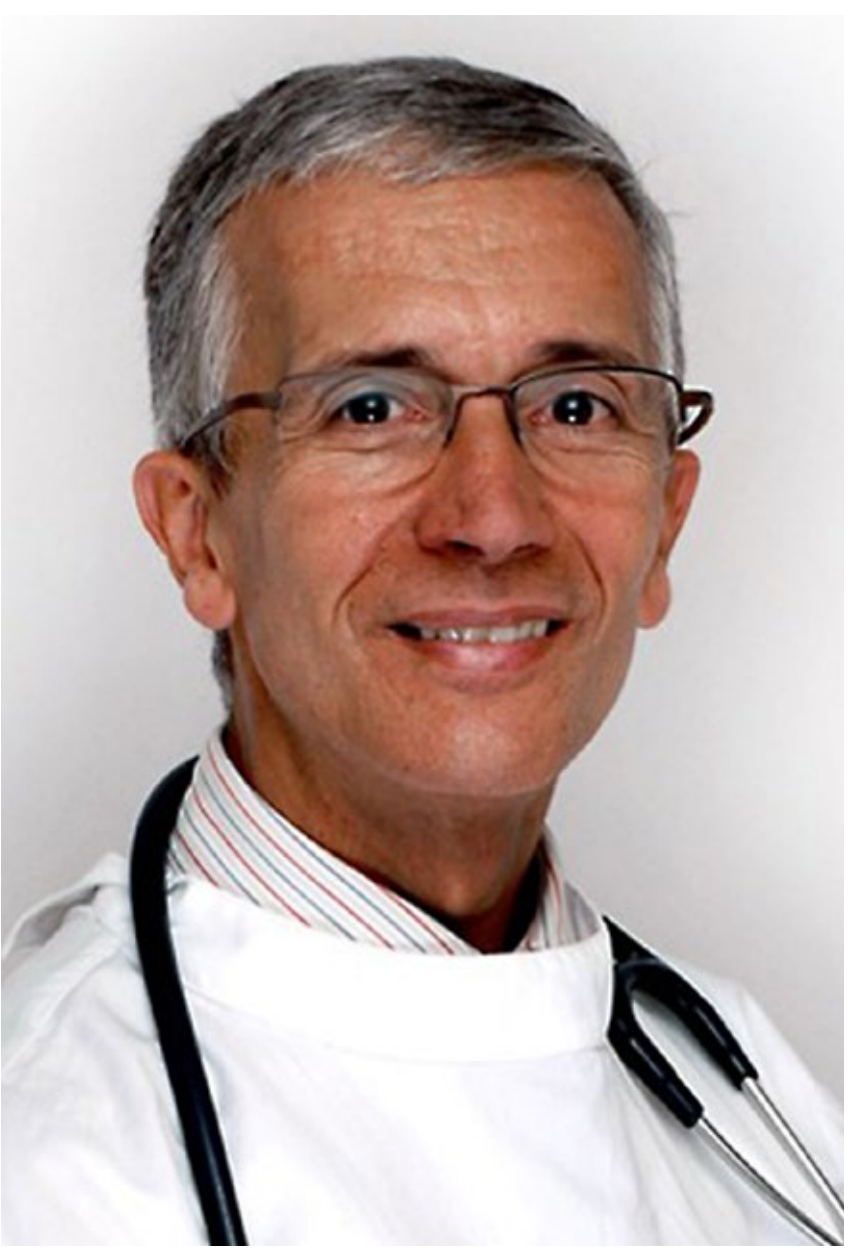

A Sociedade Portuguesa de Medicina Interna, e a Medicina Portuguesa perderam recentemente, no início de 2020, e na véspera dos seus 62 anos, uma das suas mais ilustres personalidades, o Dr. Pedro Marques da Silva.

É com amargura e saudade que vou escrever algumas palavras sobre o Pedro Marques da Silva, que tão cedo desapareceu e com ele o exemplo e a liderança de um dos nossos melhores. Palavras que se justificam, principalmente porque ele as merece e pela amizade que nos unia há mais de 35 anos, pela estreita cumplicidade que sempre nos manteve ligados, apesar de 300 km de separação, e porque Ele, concerteza (e como a Isabel me pediu) gostaria que lhe prestasse esta homenagem.

Serviço de Medicina Interna, Hospital Lusíadas, Porto, Portugal https://revista.spmi.pt - DOl:10.24950/Opiniao/E.Macedo/1/2020
O Dr. Pedro Marques da Silva, foi consultor em Medicina Interna, no Hospital de Santa Marta (CHLC), especialista em Farmacologia Clínica e Farmacoepidemiologia, especialista Europeu em Hipertensão e tinha a competência em Geriatria. Foi responsável do Núcleo de Investigação Arterial, do Ambulatório e da Consulta de Hipertensão Arterial e Dislipidémias (CHLN). Foi Research Fellow in Vascular Unit, no Hospital for Sick Children, Londres 1996. Foi assistente de Endocrinologia e Nutrição, no Hospital Clínico Universitário de Valência (1998). Foi assessor Clínico da Direção de Gestão do Risco de Medicamento no INFARMED. Foi membro do Grupo Europeu de Farmacovigilância (PhWWP), da Agência Europeia do Medicamento (EMEA). Foi Consultor da Direção Geral da Saúde e autor de muitas das Normas de Orientação Clínica publicadas. Foi membro das Direções da Sociedade Portuguesa de Aterosclerose, Tesoureiro (1997-99), Secretário-Geral (200002), Presidente (2003-2006). Foi membro da Junta Diretiva da Sociedade Iberolatinoamericana de Aterosclerosis (SILAT), Vogal (2002-2005), Secretário-Geral (2005-2008), Vice-Presidente (2008-2011). Vogal do Secretariado do Grupo de Estudos de Cardiologia Geriátrica da Sociedade Portuguesa de Cardiologia (2001-2005 e 2007-2010). Foi Coordenador-Adjunto do Núcleo de Estudos de Prevenção e Risco Vascular da SPMI. Foi Vice-Presidente da Sociedade Portuguesa de Geriatria e Gerontologia.

O Dr. Pedro Marques da Silva foi reconhecido com Prémio Nunes Correa Verdades de Faria. Também Ihe foi atribuido o título de o sócio honorário da Sociedade Portuguesa de Cardiologia, em cerimónia conjunta dom a FPC e no dia mundial do coração 2019. Foi o primeiro diploma de mérito da história da Sociedade.

O Dr. Pedro Marques da Silva foi um Humanista por excelência e foi sempre com arte, amor e compaixão que viveu a sua vida e exerceu a nobre profissão de ser Médico, que tentarei realçar nas linhas que a seguir escrevo.

O Pedro foi um anjo enviado do Além, a quem foi predestinada uma missão, neste mundo tão inconsequente, missão com um elevado grau de exigência, para quem tinha as suas limitações físicas, mas que ele aceitou com a sua reconhecida humildade, e cumpriu desde sempre como se de um sacerdócio se tratasse. A sua entrega total a essa missão, foi por todos nós sempre testemunhada, tendo ele posto os "talentos" que recebeu ao serviço do mundo, e do seu semelhante, fosse ele quem fosse, desde o mais virtuoso ou o mais pequeno e desprezado ser da sociedade. A todos serviu e ajudou, ultrapassando sempre o que the 
poderia ser exigido, mas para a sua generosidade não havia limites. A sua "Alma" era de uma grandeza imensurável, e se por momentos parecia fraquezar, logo se levantava com um grito que derrubava todas as adversidades. O seu humanismo intrínseco, associado à sua exigência, coragem e perseverança, acompanhavam sempre a sua espiritualidade na prática médica. Prática que ele exercicia com grande nobreza e virtualidade, nunca afastado dos doentes, e evitando a intersecção das tecnologias, a pulverização dos saberes, mantendo a relação única de um para um. Foi um "príncipe" humanista da Medicina Narrativa Portuguesa.

O Pedro era senhor de um conhecimento médico e científico enciclopédico, que ia da Medicina Geral, passando pela cardiologia, endocrinologia, farmacologia, epidemiologia, etc, enfim por todas as especialidades da ciência médica. Ele espalhava o seu imenso saber, deliciando os seus pares, desde na conversa de jardim, até às incontáveis palestras e intervenções que foi fazendo ao longo da sua vida, sempre com uma profundidade nanométrica, mas sem esquecer a necessária pedagogia e a mensagem clínica que a plateia deveria ouvir e recordar. São inesqueciveis as sessões clínicas "sem tema", em que sózinho enfrentava uma sala com centenas de médicos e onde cada um era livre colocar o seu problema clínico. Havia para todos a melhor e mais completa resposta ao problema.

Mas não podemos esquecer a sua vertente de investigação Clínica/Epidemiológica, que tanto gostava, e onde era um perfeccionista embora com as dificuldades inerentes a ser médico hospitalar.

Devemos sempre lembrar o enorme contributo que foram os anos de trabalho na EMEA, INFARMED, Direção Geral de Saúde, onde a sua palavra, opinião e saber foram sempre fundamentais na conlusão das decisões.

Finalmente o Pedro Marques da Silva, foi um Homem, mas também médico, de grande espiritualidade, de uma modéstia e humildade inexcedível, com uma formação moral, cristã e ética transbordante, complementadas numa verticalidade indestrutível, sentido de justiça, e sobretudo um amigo do seu amigo, e do seu doente, um ser do mundo.

\section{Responsabilidades Éticas}

Conflitos de Interesse: Os autores declaram a inexistência de conflitos de interesse na realização do presente trabalho.

Fontes de Financiamento: Não existiram fontes externas de financiamento para a realização deste artigo.

Proveniência e Revisão por Pares: Não comissionado; revisão externa por pares.

\section{Ethical Disclosures}

Conflicts of interest: The authors have no conflicts of interest to declare.

Financing Support: This work has not received any contribution, grant or scholarship

Provenance and Peer Review: Not commissioned; externally peer reviewed.

(C) Autor (es) (ou seu (s) empregador (es)) 2019. Reutilização permitida de acordo com CC BY-NC. Nenhuma reutilização comercial.

(c) Author(s) (or their employer(s)) 2019. Re-use permitted under CC BYNC. No commercial re-use.

Correspondence/Correspondência: Mário Espiga de Macedo - espigamacedo1@gmail.com

Serviço de Medicina Interna, Hospital Lusíadas, Porto, Portugal

Av. da Boavista 171, 4050-115 Porto

Received/Recebido: 13/01/2020

Accepted/Aceite: 28/01/2020

Publicado / Published: 17 de Março de 2020 